\title{
Lesão na base e concentrações de ácido indolbutírico no enraizamento de estacas apicais de figueira 'Roxo de Valinhos'
}

\section{Incision at the base and concentrations of indolbutyric acid on rooting of apical cuttings of 'Roxo de Valinhos' fig tree}

\author{
Lucas Eduardo Becker ${ }^{1}$; Rafael Pio ${ }^{2 *}$; Marcelo Angelo Campagnolo; \\ Idiana Marina Dalastra ${ }^{4}$; Paula Nogueira Curi ${ }^{5}$; Pedro Henrique Abreu Moura ${ }^{5}$
}

\begin{abstract}
Resumo
Esse trabalho teve como objetivo aumentar o potencial rizogênico das estacas coletadas da porção apical dos ramos de figueira, realizando-se ferimentos (lesão) na base das estacas e tratando com ácido indolbutírico (AIB). Estacas apicais de figueira 'Roxo de Valinhos' foram coletadas em julho, padronizadas com $20 \mathrm{~cm}$ de comprimento e diâmetro basal de $10 \mathrm{~mm}$. Os tratamentos consistiram na realização ou não de lesão na base das estacas (cortes paralelos de $2 \mathrm{~cm}$ ), e imersão em soluções contendo 0, 1000, 2000 e $3000 \mathrm{mg} \mathrm{L}^{-1}$ de AIB, por 10 segundos. As estacas foram enterradas em leito de areia umedecido, localizado dentro de telado (50\% de luminosidade), enterrando-se $3 / 4$ da estaca. Após 60 dias verificou-se que o tratamento com AIB e a lesão na base das estacas traz benefícios ao enraizamento, sendo que a concentração que obteve melhores resultados foi de $2000 \mathrm{mg} \mathrm{L}^{-1}$.

Palavras-chave: Ficus carica L, produção de mudas, AIB.
\end{abstract}

\begin{abstract}
This work aimed to increase the rhizogenic potential of cuttings collected from the apical portion of the branches of fig trees, performing injuries and treating the cuttings with indolbutyric acid (IBA). Apical cuttings of 'Roxo de Valinhos' fig tree were collected in July. The cuttings were standardized with 20 $\mathrm{cm}$ in length and basal diameter of $10 \mathrm{~mm}$. The cuttings received or not incisions at the basis (parallel cuts of $2 \mathrm{~cm}$ ) and immersed in IBA at $0,1000,2000$ and $3000 \mathrm{mg} \mathrm{L}^{-1}$ for 10 seconds. The cuttings were buried ( $3 / 4$ of the length) in moistened sand, inside a screen house ( $50 \%$ of light). After 60 days it was found that treatment with IBA benefits in the development of apical cuttings, and the concentration that achieved the best results was $2000 \mathrm{mg} \mathrm{L}^{-1}$; the use of injury at the base of the cuttings helps rooting.
\end{abstract}

Key words: Ficus carica L, propagation, IBA.

${ }^{1}$ Acadêmico em Agronomia da Universidade Estadual do Oeste do Paraná, UNIOESTE, Rua Pernambuco, 1.777, Caixa Postal 1008, Centro, 85960-000, Marechal Cândido Rondon, PR. E-mail: lucasbecker@gmail.com

2 Prof. Adjunto da Universidade Federal de Lavras, UFLA, Departamento de Agricultura, Lavras, MG. Bolsista Produtividade em Pesquisa CNPq. E-mail: rafaelpio@dag.ufla.br

${ }^{3}$ Pós-graduando do curso de Doutorado em Agronomia, Universidade Estadual do Oeste do Paraná, UNIOESTE, Rua Pernambuco, 1.777, Caixa Postal 1008, Centro, 85960-000, Marechal Cândido Rondon, PR. Bolsista do CNPq. E-mail: campa_bio@yahoo. com.br

${ }^{4}$ Pós-graduando do curso de Doutorado em Agronomia, Universidade Estadual Paulista Júlio de Mesquita Filho, UNESP, Faculdade de Ciências Agronômicas de Botucatu, Departamento de Produção Vegetal, Fazenda Experimental Lageado s/n, Caixa Postal 237, 18603-970, Botucatu, SP. Bolsista do CNPq. E-mail: ididalastra@yahoo.com.br

${ }^{5}$ Pós-graduando do curso de Mestrado em Fitotecnia, Universidade Federal de Lavras, UFLA, Departamento de Agricultura, Lavras, MG. E-mail: paulanogueiracuri@yahoo.com.br; pedrohamoura@yahoo.com.br

* Autor para correspondência 
Dentre os diversos aspectos técnicos envolvidos na ficicultura, destaca-se a dificuldade da implantação do pomar, frente ao processo adotado pelos ficicultores. Normalmente são utilizadas pelos produtores estacas oriundas da poda hibernal (junho a agosto), aproveitando apenas as estacas dotadas de 1,5 a $3,0 \mathrm{~cm}$ de diâmetro e 30 a 40 $\mathrm{cm}$ de comprimento, colocando-as diretamente na cova de plantio. Devido a não coincidência da poda hibernal com o período chuvoso, esta prática propicia um enraizamento na ordem de $40 \%$ a $60 \%$ das estacas, gerando desuniformidade no figueiral, descartando-se o restante do material propagativo devido a sua não utilização (GONÇALVES et al., 2003; ALVARENGA et al., 2007).

A solução para a propagação da figueira seria o enraizamento prévio das estacas em ambiente protegido, podendo assim utilizar estacas de menor comprimento, facilitando o manejo das mudas no viveiro, além de propiciar a seleção de plantas de qualidade e plantio no período chuvoso, possibilitando a obtenção de um pomar uniforme e vigoroso. No entanto, os índices de enraizamento das estacas da porção mediana dos ramos coletadas na época da poda hibernal da figueira são somente em torno de 50\% (NORBERTO et al., 2001).

Estacas oriundas da porção apical dos ramos de figueira 'Roxo de Valinhos' (últimos $20 \mathrm{~cm}$ ) vêm demonstrando serem promissoras na propagação da figueira. Trabalhos desenvolvidos com a utilização de estacas apicais registraram $80 \%$ de enraizamento com a aplicação de $2000 \mathrm{mg} \mathrm{L}^{-1}$ de ácido indolbutírico (AIB) (PIO et al., 2003), apresentando rápido desenvolvimento a campo após o plantio, sendo possível realizar a primeira poda de formação (40 $\mathrm{cm}$ de altura) em apenas quatro meses (PIO et al., 2004).

O uso de lesão (incisão) na base da estaca e a aplicação de fitoreguladores (AIB), ou o sinergismo das duas técnicas, tem apresentado bons resultados no enraizamento, pois as lesões expõem o câmbio e a região do córtex, aumentando a interação com o regulador vegetal. As lesões nos tecidos estimulam a divisão celular, possivelmente por romper a barreira física exercida pelos anéis de esclerênquima, aumentando a taxa respiratória e, conseqüentemente, a produção de primórdios radiculares, frente ao acúmulo de carboidratos, auxinas e síntese de etileno nessa região lesada (HARTMANN et al., 2002). Assim, em estacas feridas, haveria maior superfície para absorção de fitorreguladores e formação de raízes.

Visando aumentar o potencial rizogênico das estacas coletadas da porção apical dos ramos de figueira, realizou-se o presente trabalho, testando a lesão na base das estacas e tratamentos com ácido indolbutírico (AIB).

Estacas apicais de figueira 'Roxo de Valinhos' foram coletadas no momento da poda hibernal (início da segunda quinzena de julho de 2008) em um pomar comercial, no município de Quatro Pontes, PR. As estacas foram padronizadas com 20 $\mathrm{cm}$ de comprimento e diâmetro basal de $10 \mathrm{~mm}$. No momento do preparo das estacas foi realizado um corte reto no ápice da estaca e em bisel na base.

Os tratamentos consistiram na realização ou não de lesão na base das estacas (cortes paralelos de 2 $\mathrm{cm}$ ), com o auxílio de um canivete, com o intuito de expor a região cambial. Em seguida a base das estacas foram imersas em soluções de AIB $(0,1000$, 2000 e $3000 \mathrm{mg} \mathrm{L}^{-1}$ ) por $10 \mathrm{seg}$.

O delineamento utilizado foi o inteiramente casualizado, com os tratamentos arranjados no esquema fatorial $2 \times 4$ (lesão na base das estacas $\mathrm{x}$ doses de AIB), com 4 repetições e 10 estacas por parcela, totalizando 320 estacas.

As estacas foram dispostas em leito de areia umedecido, localizado dentro de telado $(50 \%$ de luminosidade), enterrando-se $3 / 4$ da estaca. Após 60 dias foi mensurada a porcentagem de estacas vivas, enraizadas e brotadas, comprimento médio dos brotos e das raízes, e o número médio de brotos e raízes. 
Os dados foram submetidos à análise de variância pelo teste $\mathrm{F}$, a $5 \%$ de probabilidade de erro, e as médias comparadas pelo teste de Tukey. A comparação das médias das concentrações de AIB foi feita por análise de regressão. As análises foram realizadas com o programa computacional Sistema para Análise de Variância - SISVAR.

De acordo com a análise de variância, houve interação significativa entre lesão na base das estacas e a aplicação de AIB para a porcentagem de estacas enraizadas e número médio de raízes, e da utilização de AIB para o comprimento médio das raízes.

Para a porcentagem de estacas apicais enraizadas, constatou-se que a ausência de lesão e a não aplicação de AIB proporcionou 45,2\% de enraizamento. No entanto, conforme se submeteu as estacas aconcentrações crescentes do fitorregulador, houve aumento linear no enraizamento, chegando a se obter 75,2\% incremento de 30\% (Figura 1). Já para as estacas com lesão basal, a aplicação de $2000 \mathrm{mg} \mathrm{L}^{-1}$ favoreceu o enraizamento de $100 \%$ das estacas.

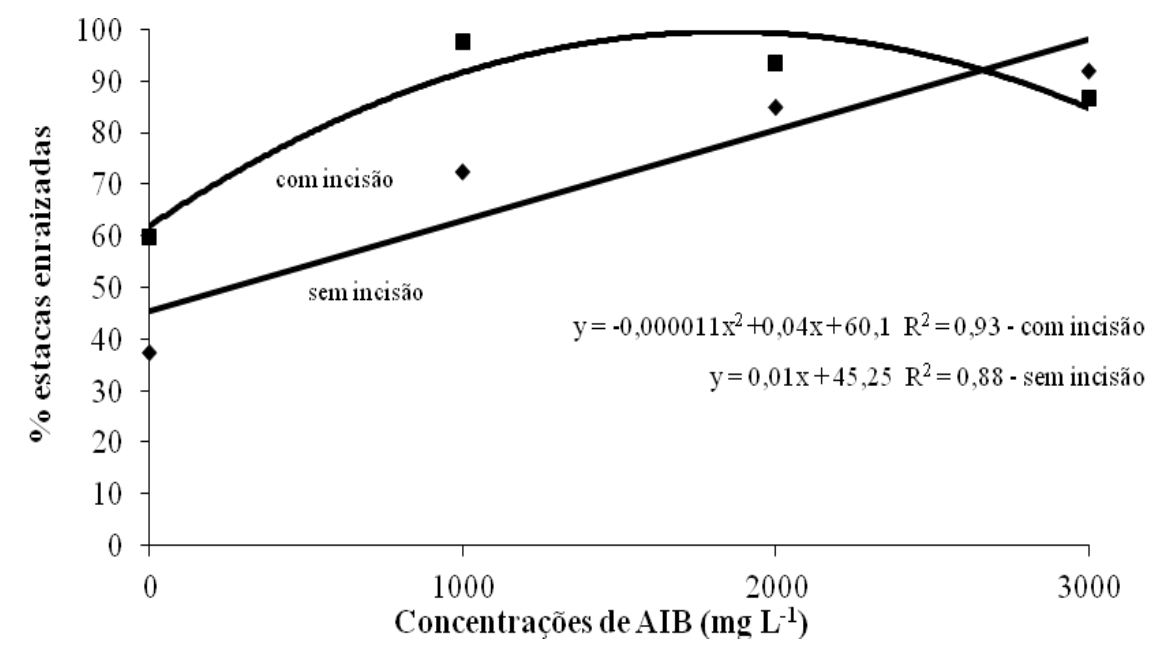

Figura 1. Porcentagem de estacas apicais enraizadas de figueira (Ficus carica L.) 'Roxo de Valinhos' submetidas à lesão na base e aplicação de concentrações de ácido indolbutírico (AIB).

Fonte: Marechal Cândido Rondon-PR, Unioeste, 2009.

Esses resultados concordam com Pio et al. (2004), que igualmente conseguiram acréscimo da rizogênese de estacas apicais de figueira com a utilização de $2000 \mathrm{mg} \mathrm{L}^{-1}$ AIB, em comparação a ausência do tratamento. Os resultados obtidos no presente trabalho foram ainda superiores aos obtidos por Pio et al. (2003), que registraram 80\% de estacas apicais enraizadas com a utilização de $2000 \mathrm{mg} \mathrm{L}^{-1}$ de AIB, ou seja, acréscimo de $20 \%$ de enraizamento. Com esses resultados, é possível aproveitar todas as estacas apicais oriundas da poda, diminuindo as perdas no processo de produção de mudas da figueira.

Para o número médio de raízes, foi constatado que as estacas que sofreram lesão na base e foram tratadas com $2000 \mathrm{mg} \mathrm{L}^{-1}$ AIB apresentaram média de 148,2 raízes (Figura 2). Já sem a lesão houve crescente enraizamento conforme o aumento das concentrações de AIB, chegando ao máximo de 75,2 raízes por estaca, com a utilização de $3000 \mathrm{mg}$ $\mathrm{L}^{-1} \mathrm{AIB}$, aproximadamente 73 raízes a menos que o tratamento mencionado, com maior concentração de AIB. 


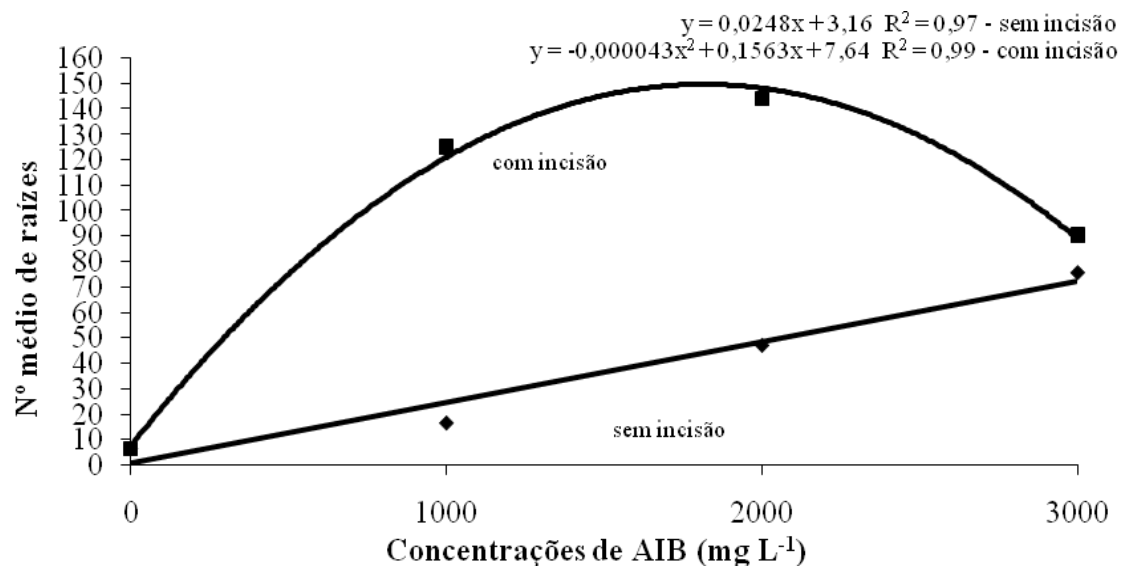

Figura 2. Número médio de raízes por estacas apicais de figueira (Ficus carica L.) 'Roxo de Valinhos' submetidas à lesão na base e aplicação de concentrações de ácido indolbutírico (AIB).

Fonte: Marechal Cândido Rondon-PR, Unioeste, 2009.

Os resultados obtidos com a utilização da lesão na base das estacas demonstrou um aumento de 53,6 raízes, em comparação aos obtidos por Ohland et al. (2009), que registraram 94,6 raízes em estacas apicais de figueira imersas em solução de $2000 \mathrm{mg} \mathrm{L}^{-1}$ AIB. O maior número de raízes em mudas propagadas por estacas é importante para o crescimento das mudas no viveiro e no plantio a campo.

Quanto ao comprimento médio das raízes, pode-se verificar que a concentração de $2000 \mathrm{mg}$ $\mathrm{L}^{-1}$ de AIB promoveu o maior crescimento (Figura 3). O bom desenvolvimento das raízes nas estacas é influenciado pelas condições internas da planta da qual foram obtidas, traduzidas pelo balanço hormonal entre inibidores, promotores e co-fatores, que interferem no crescimento das raízes, existindo, além disso, uma relação entre enraizamento e as reservas de hidratos de carbono e nitrogênio (FACHINELLO; HOFFMANN; NACHTIGAL, 2005). A auxina é o principal promotor endógeno na formação das raízes primárias (HAISSIG, 1996). Segundo Alvarenga (1990), entre as principais funções biológicas das auxinas está o crescimento de órgãos, especialmente das raízes.

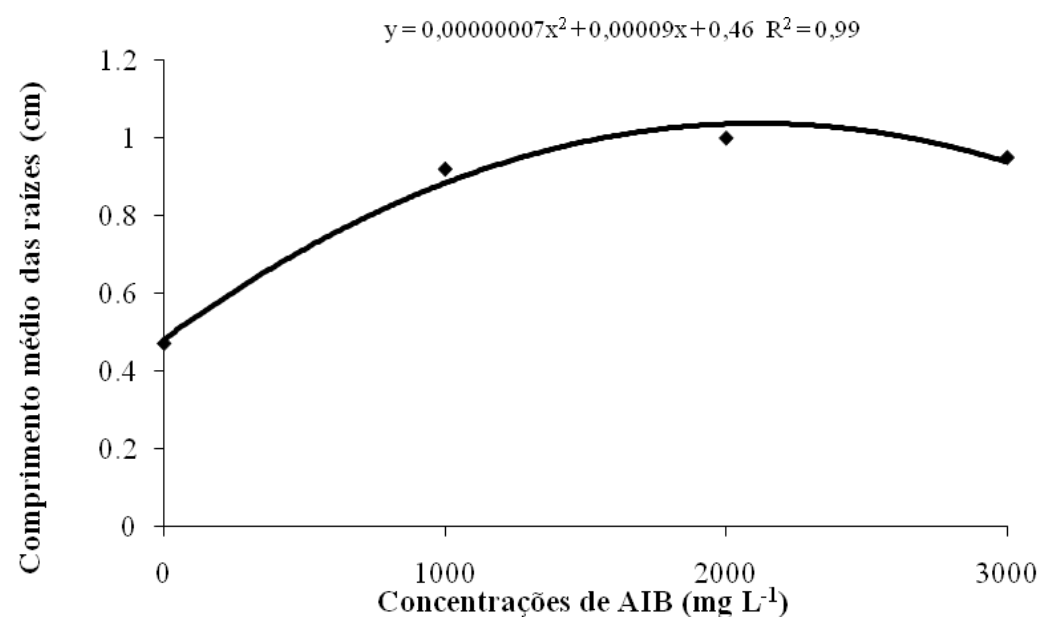

Figura 3. Comprimento médio das raízes de estacas apicais de figueira (Ficus carica L.) 'Roxo de Valinhos' submetidas a lesão na base e aplicação de concentrações de ácido indolbutírico (AIB).

Fonte: Marechal Cândido Rondon-PR, Unioeste, 2009. 
Conclui-se que a realização de lesão na base de estacas apicais da figueira cv. Roxo de Valinhos e o tratamento com AIB (2000 $\left.\mathrm{mg} \mathrm{L}^{-1}\right)$ aumentam a porcentagem de enraizamento e a quantidade de raízes emitidas.

\section{Referências}

ALVARENGA, A. A. Substâncias de crescimento e regulação do desenvolvimento vegetal. Lavras: UFLA, $1990.59 \mathrm{p}$.

ALVARENGA, A. A.; ABRAHAO, E.; FRAGUAS, J. C.; CARVALHO, V. L.; SILVA, R. A.; SANTA CECILIA, L. V. C.; CUNHA, R. L.; SILVA, V. J. Figo (Ficus carica L.). In: TRAZILBO JUNIOR, J. P.; MADELAINE, V. (Org.). 101 Culturas - manual de tecnologias agrícolas. Belo Horizonte: EPAMIG, 2007. p. 365-372.

FACHINELLO, J. C.; HOFFMANN, A.; NACHTIGAL, J. C. Propagação de plantas frutíferas. Brasília: Embrapa, 2005. $221 \mathrm{p}$.

GONÇALVES, F. C.; CHALFUN, N. N. J.; ALVARENGA, A. A.; MIRANDA, C. S. de. Influência da forma de acondicionamento sob frio na sobrevivência de mudas de figueira. Ciência Agrotecnologica, Lavras, v. 27, n. 4, p. 798-803, 2003.

HAISSIG, B. E. Metabolic process in adventitious rooting of cuttings. In: JACKSON, M. B. (Ed.). New root formation in plants and cuttings. Dordrecht: Matinus Nijhoff, 1996. p .141-190.
HARTMANN, H. T.; KESTER, D. E.; DAVIES JUNIOR, F. T.; GENEVE, R. L. Plant propagation: principles and practices. 7. ed. New Jersey: Prentice Hall, 2002. 880 p.

NORBERTO, P. M.; CHALFUN, N. N. J.; PASQUAL, M.; VEIGA, R. D.; PEREIRA, G. E.; MOTA, J. H. Efeito da época de estaquia e do AIB no enraizamento de estacas de figueira (Ficus carica L.). Ciência e Agrotecnologia, Lavras, v. 25, n. 3, p. 533-541, 2001.

OHLAND, T.; PIO, R.; CHAGAS, E. A.; BARBOSA, W.; DALASTRA, I. M.; KOTZ, T. E. Enraizamento de estacas apicais lenhosas de figueira 'Roxo de Valinhos' com a aplicação de AIB e cianamida hidrogenada. Revista Brasileira de Fruticultura, Cruz das Almas, v. 31, n. 1, p. 273-279, 2009.

PIO, R.; RAMOS, J. D.; CHALFUN, N. N. J.; COELHO, J. H. C.; GONTIJO, T. C. A.; CARRIJO, E. P. Enraizamento de estacas apicais de figueira tratadas com sacarose e ácido indolbutírico por imersão rápida. Revista Brasileira de Agrociência, Jaboticabal, v. 9, n. 1, p. 35-38, 2003.

PIO, R.; RAMOS, J. D.; CHALFUN, N. N. J.; COELHO, J. H. C.; GONTIJO, T. C. A.; CARRIJO, E. P.; VILLA, F. Enraizamento adventícios de estacas apicais de figueira e desenvolvimento inicial das plantas no campo. Ciência e Agrotecnologia, Lavras, v. 28, n. 1, p. 215-221, 2004. 
